\title{
Correspondence
}

\section{Resource implications of changes in practice}

\section{DeAR SirS}

We recently discussed at our monthly meeting the College document on 'The Management of Potentially Violent Patients in the Community'. It was in the main well received although there were misgivings about the degree to which one could determine which patients should be subject to this document's guidelines. The discussion turned to the consultant time required to implement the recommendations in this document.

This followed other discussions during the year on the Care Programme Approach, The Health Service Circular on Discharge Procedures, The Patients Charter and through the contracting process, increasing emphasis on provision of services to primary care. We anticipate receiving the recommendations of the Reed Committee which are anticipated to have major implications for general adult psychiatry.

The sheer number of such reports and health circulars which carry with them major resource implications for psychiatry led to a lively debate on how we are to implement them in the face of no development or growth money and, particularly in the case of Newcastle, a substantial decrease in the mental health budget for the coming year. The White Paper has led to an increased emphasis on clinical involvement of consultants in management and a requirement to devote sessional time to medical audit. Because of our rapidly expanding community services, existing manpower is already working to capacity and spiralling demand has been met only by considerable personal dedication.

Although any one of these developments could be incorporated into existing workloads, the sheer number and pace of developments means that this cannot be done. We gave active consideration to which aspects of our service we should abandon in order to implement these changes in practice in the knowledge that we have little hope of any expansion in the mental health budget.

We wondered if other colleagues in the country have given consideration of how to manage the resource implications of these developments. We feel that the College's guidelines of 'norms' for medical manpower must now be out of date and need revision. We would welcome comment from Members and Fellows of the College.

DR J. C. O'Grady

Acting Chair, Division of Psychiatry Newcastle NHS Mental Health Trust

Newcastle General Hospital

Newcastle upon Tyne

NE4 6BE

\section{Management training - finding what we need}

DeAR SIRS

The day before I read Danitza Jadresic's comment on management training (Psychiatric Bulletin, February $1992,16,86-87$ ), yet another invitation to a management course landed on my desk. As usual there was scant information on the course facilitators, topics covered, and style of learning involved. I sympathise with Dr Jadresic's pessimism about courses which do not meet our needs but have been fortunate to join an excellent management development course for senior registrars, coordinated and funded by Yorkshire regional health authority.

It took months to assess the management courses available and most were rejected because they did not meet my needs. The specific aims of the course I chose are: to introduce participants to basic managerial skills and concepts; to provide an opportunity to make personal preparation for the management aspects of a consultant's role in a developing organisation; and to build a supportive group of colleagues to enable those aims to be met. There are four course tutors from a variety of public and private sector backgrounds. All are now committed to management learning and development. The course is semistructured, and has been modified from the start to meet our expressed needs. The emphasis is on large and small group learning.

It does not set out to answer questions or disseminate facts in the traditional medical teaching model. Instead we are encouraged to think for ourselves, say what we think and feel, listen to ourselves, value ourselves and the others in our group. Initially, some of the senior registrars had reservations about this approach. Now, in the midst of the course, I think we are all finding valuable insights into ourselves, our colleagues and the organisations in which we work. 
I have been surprised at the common ground between management development and psychiatry: transactional analysis, gestalt, listening skills, positive belief cycles. Although my knowledge of this common ground is sketchy, my postgraduate psychiatric training has already re-kindled management skills that six years of medical school and house jobs conspired to obliterate. In addition, much of the course material is directly applicable to my clinical work.

I am not concerned about what is 'required of me' as a manager but rather what I require of my organisation. I also realise that I have had a range of effective management skills for years, without being aware of them, and that I can continue to develop them in the light of future needs. All of my colleagues in training have extensive management ability, but rarely acknowledge this fact themselves. Management training can help us to improve existing talents, and it is up to us to critically appraise, and choose, the courses which suit our needs.

The General Infirmary

DAvid Yeomans

Leeds LSI 3EX

\section{Management training}

DeAr SirS

Dr Jadresic's paper on management training (Psychiatric Bulletin, February 1992, 16, 86-87) serves as an important reminder of controversy surrounding management training for clinicians. Griffiths management reform is not just about a few doctors becoming general managers, but about all doctors becoming managerially accountable for the quality of their service and the resources they commit (Waters, 1985). The trend towards cost-efficiency and competition within internal markets further strengthens the case for the acquisition of effective management skills. The CTC working party report on management training (1990) provides a review of available alternatives and makes recommendations useful for those contemplating management training. Any trainee embarking on management training should consider very carefully the alternatives, assess their needs and determine their own aims and objectives. It is often necessary to choose and/or tailor an individual training package.

Even those "with a prioritised and single interest in clinical practice and research" need to realise that the acquisition of management skills is an on-going experience which starts early in one's career, and may usefully be supplemented by attending selected courses.

O. JUNAID

Queen's Medical Centre

Nottingham NG7 2UH

\section{References}

The CTC Working Party Report on Management Training (1990). Psychiatric Bulletin, 14, 373-378.

WATERS, H. (1985) Management training for clinicians. British Medical Journal, 291, 1294-1295.

\section{DeAr Sirs}

I was interested to read Dr Jadresic's article entitled 'Management Training - what do we need?' (Psychiatric Bulletin, February 1992, 16, 86-87) where it was suggested that doctors might learn more about management by following a manager around for the day than on a formal course. I would support this suggestion for registrars/senior registrars, after spending a day "attached" to our Unit General Manager. It involved numerous meetings with many health professionals (clinicians and management) between $8.30 \mathrm{a} . \mathrm{m}$. and 7.30 p.m. I came to understand much more about management issues, Trust funds and the skills involved in chairing meetings etc.

I also made my contribution, giving unsolicited advice on the dangers of excessive caffeine intake and hypoglycaemia. We didn't stop for lunch.

St Edward's Hospital, Cheddleton

G. M. KEARNEY

(Keele Registrar Rotational Training Scheme)

\section{Patient involvement in their psychiatric care}

Dear Sirs

In response to the concerns I raised in the wake of the MIND People First survey, Drs Phaterpekar and Abbott (Psychiatric Bulletin, February 1992, 16, 112-113) suggest that I "should be reassured that considerable advances have been made with regard to patient involvement in their psychiatric care". May I make the following points?

(a) Local monitoring of satisfaction with services by those delivering care is confounded by the issue of power. A positive response bias is likely when people in hospital are asked their views by those who control their therapeutic fate and, in the case of formally detained patients, their liberty. Our survey was a research exercise, as we were independent of service delivery and this could explain why our data offer much less comfort to clinicians about the quality of in-patient services, as assessed by users. If psychiatrists are really concerned with service quality I hope that they give due attention to this in the research funding bodies they control. For instance, in the list of priorities set by the MRC committee looking at research into "schizophrenia" in 1988, service evaluation to patients (not by them) came a lame 8 out of 10 targets. Traditional 